\title{
Analysis of serve and serve return on different surfaces in elite tennis players
}

\section{Análise de saque e devolução de saque em diferentes tipos de quadra em jogadores de tênis de elite}

\author{
Victor Paiva de Faria Melonio ${ }^{1}$ \\ (D) https://orcid.org/0000-0002-1898-3637 \\ Marcelo Saldanha Aoki ${ }^{2}$ \\ (D) https://orcid.org/0000-0001-7803-6829 \\ Ademir Felipe Schultz Arruda ${ }^{1}$ \\ (D) https://orcid.org/0000-0003-4035-0104 \\ Darlan Souza² \\ (D) https://orcid.org/0000-0001-5795-5658 \\ Caroline Dário Capitani ${ }^{3}$ \\ (D) https://orcid.org/0000-0002-3466-6148 \\ Alexandre Moreira ${ }^{\dagger}$ \\ (D) https://orcid.org/0000-0002-4609-1839
}

Abstract - The aim of the current study was to analyze players' interactions in serve and serve return situations and examine the way points were decided due to players' positions and surfaces. Fourteen ATP 1000 tournament matches were analyzed ( 7 on hard surface; 7 on clay surface). The type of surface did not affect the way points ended $\left(X^{2}=9.26 ; p>0.05\right)$ but did influence serve return vertical positioning $\left(X^{2}=270.86 ; p<0.001\right)$. The return positioning, both lateral $\left(X^{2}=92.68 ; p<0.001\right.$ on deuce side $-X^{2}=78.98 ; p<0.001$ on advantage side $)$ and vertical $\left(X^{2}=33.59 ; p<0.001\right)$, and the type of serve $\left(X^{2}=45.13 ; p<0.001\right)$ affected the way points were decided. The results from the present study suggest that tennis players should use, or at least seek, strategies based on aggressiveness and consistency of the $1^{\text {st }}$ serve and also indicate that in the $2^{\text {nd }}$ serve return, players are more offensive, and that on hard surfaces, players stand a few steps inside the court to return the serve, differently from clay surfaces. It recommended that serve returns should combine aggression, by inside the court positioning, and accuracy.

Key words: Athletic performance; Data analysis; Racquet sports.

Resumo - O objetivo do presente estudo foi analisar as interaçōes dos jogadores em situações de saque e retorno de saque e examinar como os pontos foram decididos em função do posicionamento em quadra e dos tipos de superficie. Quatorze partidas do torneio ATP 1000 foram analisadas (7 em superfície dura; 7 em superfície de saibro). O tipo de piso não influenciou a forma como os pontos são definidos $\left(X^{2}=9,26 ; p>0,05\right)$, mas apresentou efeito sobre o posicionamento vertical na devolução de saque $\left(X^{2}=270,86 ; p<0.001\right)$. O posicionamento na devolução de saque, tanto vertical como lateral (no lado de iguais $X^{2}=92,68 ; p<0,001$ e no lado da vantagem $\left.X^{2}=78,98 ; p<0,001\right)$, e o tipo de saque $\left(X^{2}=45,13 ; p<0.001\right)$ afetaram a forma como os pontos foram definidos. Os resultados do presente estudo sugerem que os tenistas devem usar, ou pelo menos buscar, estratégias de jogo baseadas na agressividade e consistência do $1^{\circ}$ saque. Os resultados também indicam que na devolução do $2^{\circ}$ saque os jogadores são mais ofensivos, e que nas superfícies duras os jogadores ficam alguns passos dentro da quadra para devolver o saque, diferentemente das superfícies de saibro. Recomenda-se que devoluçôes de saque combinem agressividade, por posicionamento dentro da quadra, e acurácia.

Palavras-chave: Análise de dados; Desempenho atlético; Esportes de raquete.
1 University of São Paulo. School of Physical Education and Sport. São Paulo, SP. Brazil.

2 University of São Paulo. School of Arts, Sciences and Humanities. São Paulo, SP. Brazil.

3 University of Campinas. School of Applied Sciences. São Paulo, SP. Brazil.

Received: August 20, 2020 Accepted: December 08, 2020

How to cite this article Melonio VPF, Aoki MS, Arruda AFS, Souza D, Capitani CD, Moreira A. Analysis of serve and serve return on different surfaces in elite tennis players. Rev Bras Cineantropom Desempenho Hum 2021; 23:e76603. D0l: http://doi. org/10.1590/1980-0037.2021v23e76603

Copyright: This work is licensed under a Creative Commons Attribution 4.0 International License. 


\section{INTRODUCTION}

Tennis is a complex and dynamic sport that involves recurrent decisionmaking of players. These decisions are made based on actions taken by tennis players, e.g., types of service, serve return techniques, "strokes" (technical actions) performed during a rally, winners attempts, and unforced errors ${ }^{1}$. In addition, it is possible to identify other performance indicators that may aid in the analysis of tennis players' decision-making and performance. Among them, distance covered by players and their positioning have been examined, as well as how "aggressive" the point was, taking into account the characteristic of rallies and whether points were won at backcourt or at net ${ }^{2}$.

In a systemic approach of the game, environmental "constraints", such as court surface, surface characteristics, and player's positioning ${ }^{3}$ might influence decisions and patterns associated with the decision of points. The International Tennis Federation ${ }^{4}$ classifies surfaces into 3 categories: $1^{\text {st: }}$ slow surface, e.g., clay courts (e.g. of Roland Garros tournament), $2^{\text {nd }}$ : medium surface (e.g., hard courts of the U.S. Open and Australian Open tournaments), and $3^{\text {rd. }}$ fast surface (e.g., grass courts of Wimbledon). A1though the analysis of matches held on fast courts has indicated advantage of players with more first serve $(1 \mathrm{~S})$ aces, there is still controversy related to the role of serving to the overall performance on fast courts compared to slow courts, notably during Grand Slam tournaments ${ }^{3,5}$. Serve speed and strategies used in different surfaces were examined in Grand Slam tournaments; in general, the results of these studies have showed that tennis players with a higher $1 \mathrm{~S}$ percentage had a higher percentage of points won, regardless of court surface ${ }^{3,6}$.

Regarding "serve", it is reasonable to admit that its effectiveness also depends on the receiver's skill and serve return capacity. Therefore, the server / receiver interaction must be used when analyzing serve effectiveness. In serve return situations, players must react quickly and, in many cases, strike the ball at $200 \mathrm{~km} / \mathrm{h}$. Additionally, players must adapt and adjust the serve return considering variations on ball amplitude and direction. These conditions reveal the complex and adaptive nature of "response" (serve return) in tennis, while showing the importance of this "stroke" effectiveness in contemporary tennis. However, few studies have examined serve return tactical features and positioning, considering this action in an adaptive and dynamic perspective.

Following this approach, Collison and Hughes ${ }^{6}$ verified that the average of $15 \%$ of all points are decided by serve return in best of 3 sets games played on clay surfaces, whereas $20 \%$ of all points are decided in the same situation on fast courts. Although it is more difficult to return serves on fast courts, good serve return increases the percentage of points won on fast courts (40\%), as compared to clay surfaces $(30 \%)^{6}$. These results suggest that the serve return interaction is crucial in determining the point outcome. However, the dynamics associated with serve return on different 
surfaces is not completely understood. Thus, the aim of this study was to analyze players' interactions in serve and serve return situations and the way that points were decided by players' initial position and also by surfaces on which matches were played.

\section{METHODS}

\section{Sample}

Data from 16 players were analyzed from video recordings of tennis matches. Eight players analyzed on fast courts had $11.6 \pm 3.0$ years of experience on the ATP circuit; $28.9 \pm 3.5$ years of age and $187 \pm 7 \mathrm{~cm}$ in height. The lowest ranking position among these players, immediately before the beginning of the assessed competition, was $42^{\text {nd }}$ and the highest was $3^{\text {rd }}$. Eight players analyzed on slow courts had $10.0 \pm 2.4$ years of experience in the circuit; $26.9 \pm 2.7$ years of age and $1.85 \pm 0.03 \mathrm{~m}$ in height (public domain data). The player in the lowest ranking position among them immediately before the beginning of the competition was $49^{\text {th }}$ and the highest, $1^{\text {st }}$.

\section{Experimental design}

Fourteen official matches were chosen from two ATP Masters 1000 tournaments in 2013. These tournaments were chosen due to their importance and because players earn more world ranking points in these events than regular tournaments. A tournament played on hard court and another on clay court were assessed; for each one, quarterfinals, semifinals and final matches were analyzed in a total of 7 matches per tournament. At the end of data collection, 938 points for hard courts and 894 points for clay courts were available for analyses.

\section{Match videos analysis}

Recordings of television broadcasts of matches chosen for the study were digitalized to perform data collection using SportsCode ${ }^{\circledR}$ GameBraker software (version GameBreaker 9 for Macintosh). In the software, tags were created in a code window to identify the way points were decided and players' positioning. Each time an action category was observed in the video, a command was given in the keyboard to register the action at that moment.

\section{Analyzed variables}

The way points were decided. To understand how serve and serve return affected the dynamics of the game, each point was analyzed in 7 categories according to what occurred until the $4^{\text {th }}$ shot exchanged (counting the serve) or until the end of the point. Aces and double faults were not taken into account.

- Return Winner (RW): the server fails to strike the ball after the serve return; 
- Return error (RE): receiver hits the ball but fails to put it on court

- Third ball winner (3BW): following the serve return, the server hits a winning shot;

- Third ball error (3BE): server misses the shot following the opponent's return;

- Fourth ball winner (4BW): the receiver returns the serve and strikes an indefensible ball in his next shot;

- Fourth ball error (4BE): the receiver returns the serve, but misses the next shot.

- Rally (RALLY): the point continues after the fourth stroke.

- Serve analysis. Serves were classified into two categories: first serve $(1 \mathrm{~S})$ and second serve $(2 \mathrm{~S})$.

- Return of serve lateral positioning. Return of serve contact point location was classified according to Hizan et al. ${ }^{7}$ proposition, and was determined by the ball location at the moment it touched the racket. Positions are illustrated in Figure 1.

- Return of serve vertical positioning. The player's serve return vertical position was determined by the player's feet position at the moment of ball contact with the racket: behind the baseline (BB) or inside the court (IC).

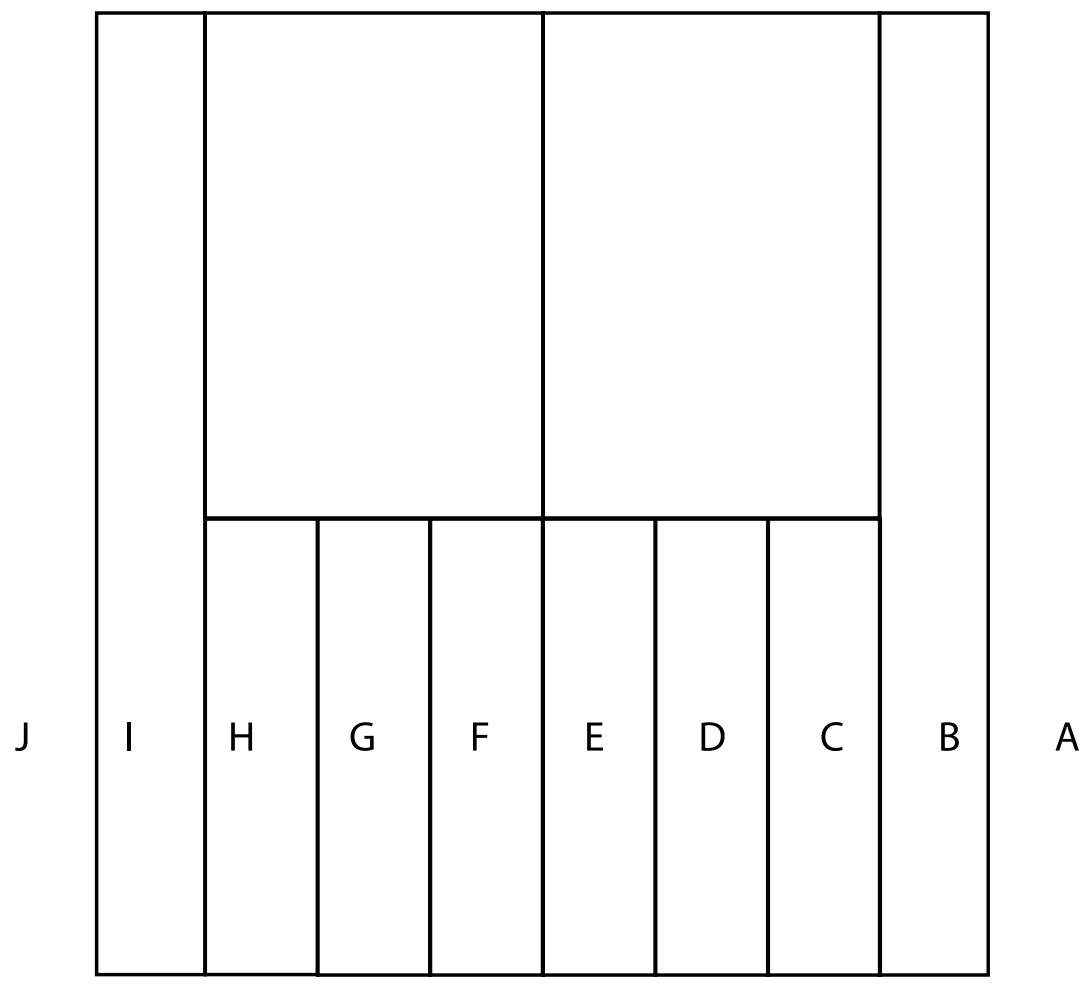

Figure 1. Serve return lateral positioning.

\section{Statistical analysis}

Data are described in terms of both absolute and relative frequency. Chisquare $\left(\mathrm{X}^{2}\right)$ test was calculated to determine whether there was significant 
association between pairs of the following variables: (a) court vs. the way points were decided, (b) court vs. serve return vertical positioning, (c) serve return lateral positioning vs. how points were decided, (d) serve vs. the way points were decided, (e) serve vs. serve return vertical positioning, (f) serve vs. serve return lateral positioning. The significance level adopted was 5\% ( $\mathrm{p} \leq 0.05)$.

\section{RESULTS}

Overall, 1,832 points from 14 ATP 1000 tournament matches were observed; 7 matches were played on clay courts (total of 894 points) and 7 played on fast (hard) courts (total of 938 points); 1,070 points were played with $1 \mathrm{~S}$ and 762 points with $2 \mathrm{~S}$. A lower frequency of points played with $1 \mathrm{~S}$ in hard courts $(522-55.65 \%)$ was found compared to points played on clay (548-61.30\%). In both courts, a greater frequency of 1S (522-55.65\% on fast and $548-61.30 \%$ on clay) compared to $2 \mathrm{~S}$ ( $416-44.35 \%$ on fast and $346-38.70 \%$ on clay) was found.

Figure 2 shows the type of serve that influenced players' serve return vertical positioning. A significant difference was observed $\left(X^{2}=460.50 ; p\right.$ $<0.001)$. IC return positioning of $2 \mathrm{~S}$ on fast (hard) court $(313-75.24 \%)$ was higher than observed on clay courts $(56-16.18 \%)$. In $1 \mathrm{~S}$, there is predominance in the $\mathrm{BB}$ position, both on hard court $(545-89.46 \%)$ and clay court $(290-99.45 \%)$.

The type of surface did not affect the way points ended $\left(X^{2}=9.26 ; \mathrm{p}\right.$ $>0.05)$ but did influence serve return vertical positioning $\left(X^{2}=270.86\right.$; $\mathrm{p}<0.001)$. Although on both surfaces, most returns have been made BB (570-60.77\% - hard court and 835-93.40\% - clay court); on hard courts, players were positioned with a higher frequency at IC $(368-39.23 \%)$ than on clay courts $(59-6.60 \%)$ (Figure 2$)$.

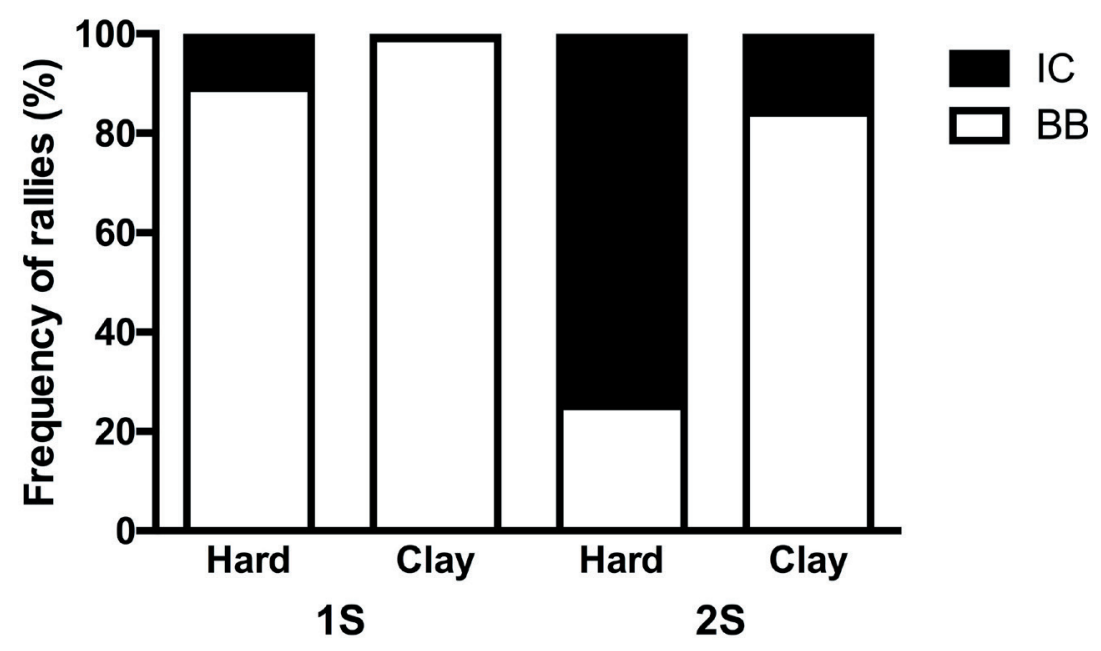

Figure 2. Serve return vertical positioning distribution based on serve type and surface

Type of service affects players' serve return lateral positioning both on "deuce side" $\left(X^{2}=123.32 ; \mathrm{p}<0.001\right)$ and on "advantage side" $\left(X^{2}=163.99\right.$; 
$\mathrm{p}<0.001) .1 \mathrm{~S}$ returns occurred with a higher frequency in areas farthest from receiver's initial positioning: $263-47.05 \%$ on $\mathrm{A}$ and $\mathrm{E}$ positions (deuce side) and $250-48.93 \%$ on $\mathrm{F}$ and $\mathrm{J}$ positions (advantage side). $2 \mathrm{~S}$ returns occurred less in these areas: $69-18.13 \%$ in $\mathrm{A}$ and $\mathrm{E}$ positions (deuce side) and $60-15.96 \%$ in $\mathrm{F}$ and $\mathrm{J}$ positions (advantage side). A higher frequency of $2 \mathrm{~S}$ returns on the player's backhand was observed.
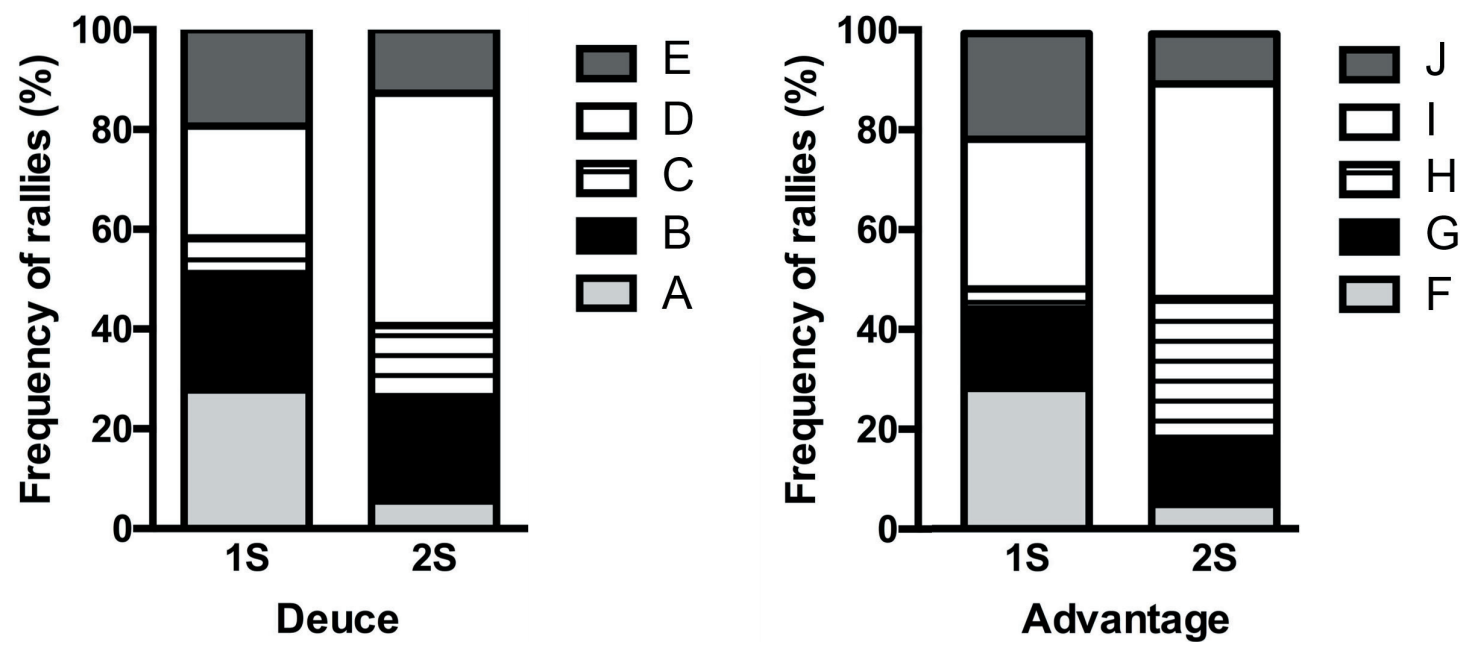

Figure 3. Lateral positioning distribution in serve return based on serve type.

Figure 4 shows that the service type influenced the way points were decided $\left(X^{2}=45.13 ; \mathrm{p}<0.001\right)$. There have been more RW and RALLY points, and less RE in $2 \mathrm{~S}$ returns (18-2.36\%; $448-58.79 \%$; $82-10.76 \%)$, compared with $1 \mathrm{~S}(7-0.65 \% ; 548-51.21 \% ; 213-19.91 \%)$, respectively.

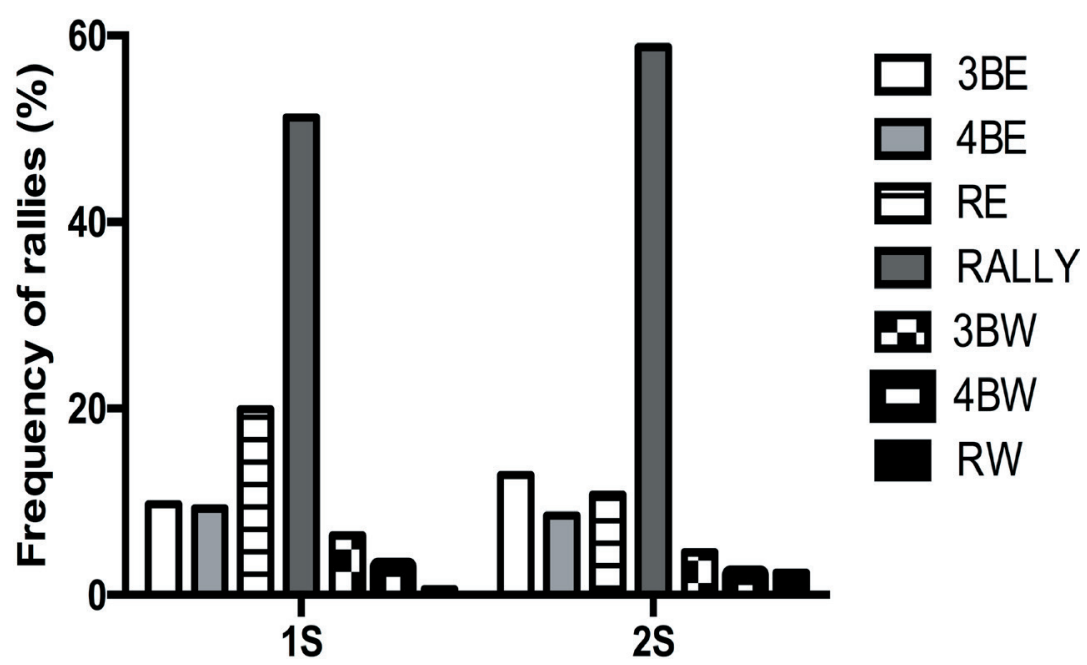

Figure 4. Distribution of points decided in $1 \mathrm{~S}$ and $2 \mathrm{~S}$.

Figure 5 shows that the serve return lateral location influences the way points are decided both on deuce side $\left(5 \mathrm{~A} ; \mathrm{X}^{2}=92.68 ; \mathrm{p}<0.001\right)$ and advantage side $\left(5 \mathrm{~B} ; \mathrm{X}^{2}=78.98 ; \mathrm{p}<0.001\right)$. Most points are decided by $\mathrm{RW}$ when 
service was returned in the $\mathrm{B}$ position $(5-41.67 \%)$ and in the $\mathrm{H}$ position $(12$ $-53.85 \%)$. Most points decided by 3BW occurred when players returned the serve on A (36.73\%) and J positions (35.19\%). Few RALLYs were observed when the receiver returned the ball inside the court away from the opponent.

A

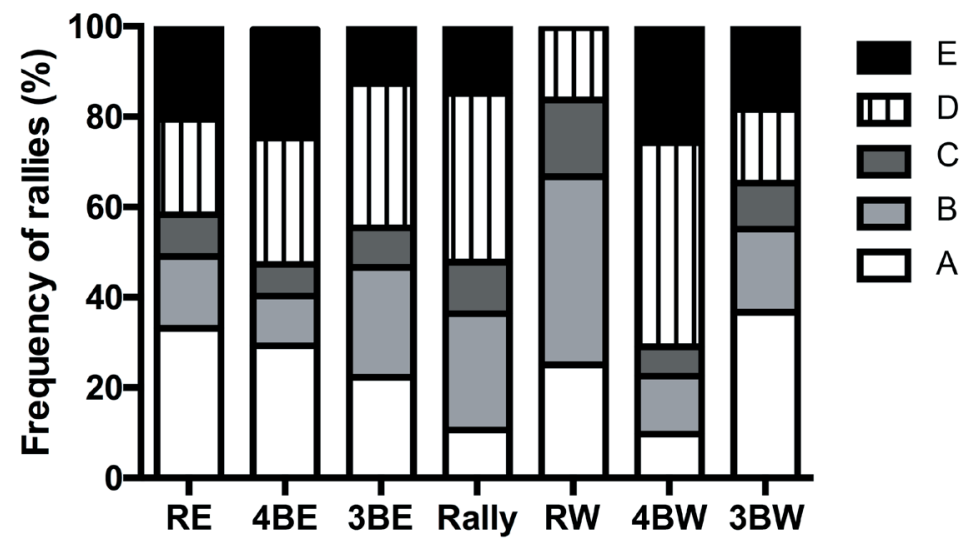

B

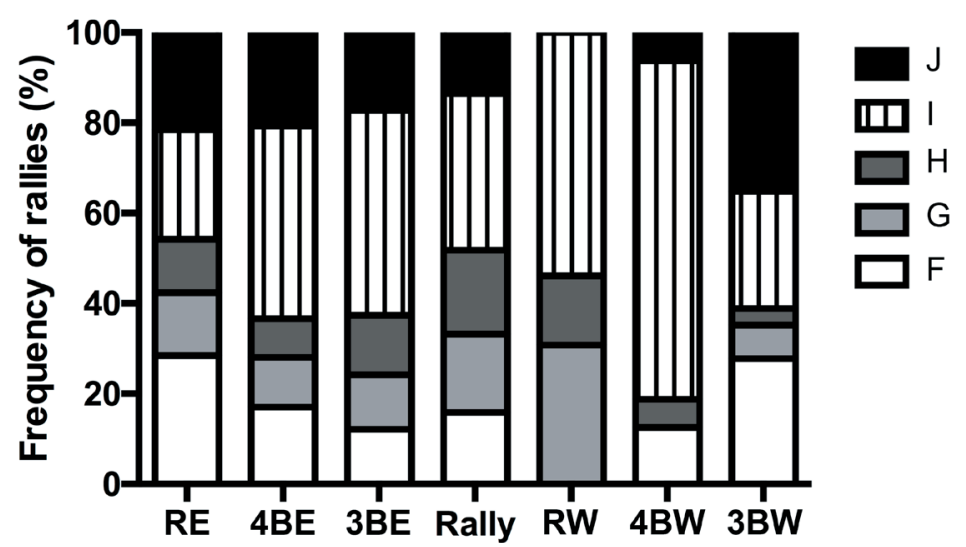

Figure 5. Points decided according to serve return positions. 5A. Deuce side; 5B. Advantage side.

\section{DISCUSSION}

The most important results from this study demonstrate that the types of serve and the receiver positioning influenced the way points were decided. The receiver position, in turn, seems to have been influenced by the opponent's serve. It was also found that the court surface influenced the type of serve and serve return vertical positioning, although it has not influenced the way points were decided.

Results of the present study suggest that a higher $1 \mathrm{~S}$ percentage means a higher percentage of $1 \mathrm{~S}$ points. The increased number of points won directly from serve return error after $1 \mathrm{~S}$ found in this study corroborates results of Haake et al. ${ }^{8}$, who showed a higher frequency of aces and serve return errors 
in $1 \mathrm{~S}$ due to the service's higher speed. A higher $1 \mathrm{~S}$ percentage indirectly increases serve returns made a few steps away from baseline, influencing the way points are decided, most of them decided by $3 \mathrm{BW}$ and RE.

Previous studies ${ }^{3,9}$ confirm control of points by higher $1 \mathrm{~S}$ percentage that move opponents to the back and side of the court, returning the ball to the center of the court, or that land the ball away from the opponent. O'Donoghue and Ingram ${ }^{3}$ reported a significant relationship between $1 \mathrm{~S}$ percentage and the probability of winning rally points in 252 Grand Slam games examined in the study. Similarly, Gillet et al. ${ }^{9}$ observed that elite players have a higher percentage $(50.30 \%)$ of points won when their first service hit the "T". These results are in agreement with models proposed by Carvalho et al. ${ }^{10}$ and Palut and Zanone ${ }^{11}$, who reported that players interact seeking to draw their opponents backwards and to the sides, landing balls as far away as possible from the opponent's body/positioning, so as to break the interpersonal coordination pattern, delay the opponent's reaction to create an attack opportunity and win the point.

The findings of the present study indicate that the type of service also influenced players' vertical positioning when returning serves. This result corroborates Gullikson and $\mathrm{MacCurdy}{ }^{12}$, who suggest that in faster (hard) surfaces, receivers must step inside the court. In the present study, it was observed that $75.24 \%$ of $2 \mathrm{~S}$ returns on fast (hard) surfaces were performed at IC, whereas players stepped forward at IC in $16.18 \%$ of points won on clay courts.

$2 \mathrm{~S}$ is usually more conservative, resulting in decreased serve speed and increased receiver's reaction time ${ }^{5}$. This feature of $2 \mathrm{~S}$ enables positioning closer to the net, reducing the reaction time and avoiding that the opponent dominates the point from the serve. The present study confirms neutralization of server's actions by stepping inside the court by lower frequency of 3BW and 4BE observed when returns took place at IC (16$15.53 \%$ and $28-17.07 \%$, respectively) compared to BB $(87-84.47 \%$ and $136-82.93 \%$, respectively).

Regarding types of serve and the way points are decided, more rallies were observed in $2 \mathrm{~S}(448-58.79 \%)$ than in $1 \mathrm{~S}(548-51.21 \%)$. Since with more time for technical preparations of stroke in $2 \mathrm{~S}$, players' serve return would not lose so much power and precision, allowing them to maintain equal chances to win the point. A higher number of points decided in $\mathrm{RW}$ was also found in $2 \mathrm{~S}$ returns $(18-2.36 \%)$, in contrast to $1 \mathrm{~S}$ returns $(7-0.65 \%)$. One of the possible explanations is given by Kleinoder and Mester $^{13}$, who reported that in $2 \mathrm{~S}$ returns, players generate more speed in the upper limbs and in the racket; therefore, they are more aggressive when reacting to this serve, a dynamics not present in $1 \mathrm{~S}$ returns. Considering results from Kleinoder and Mester ${ }^{13}$ and results from the present study, receivers seem to step inside the court when they want to be more "aggressive" in their returns. This statement is in accordance with Carvalho et al. ${ }^{10}$ and Hughes and Franks ${ }^{14}$, who reported that being positioned closer to the net (or to the wall, in the case of squash) is a more favourable position to throw the opponent out of balance. 
On clay courts, the ball bounces more slowly after contact with the surface compared to medium and fast courts, increasing reaction and giving more time to reach the ball. For this reason, more strokes per point and points with a greater duration are expected ${ }^{3}$. However, this study did not give evidence of a dependency between type of surface and the way points were decided. Despite the difficulty to explain these results, it is possible to speculate that in the past few years, the development of tennis players' physical fitness had allowed them to increase the number of balls exchanged per point, for both clay and fast courts. This hypothesis, though highly speculative, could be empirically tested in future studies, comparing different level players, or even seeking possible associations between changes in players' physical performance and changes in the pattern of strokes per point and duration of points. However, it is worth mentioning that these investigations should be contemplated by a systemic and interactive approach, in which the player evaluated and his performance should be analyzed considering the interaction with opponents and respective environmental constraints.

Although surface types did not influence the way points were decided, a higher number of return errors on fast (hard) courts (167 - 17.80\%) compared to clay courts (128 - 14.32\%) was observed. These data confirm results obtained by O'Donoghue and Ingram ${ }^{3}$, who reported a higher number of serve return unforced errors on fast courts compared to clay courts, because serve is slower and produce lower bounce after contact of the ball with the hard surface. Gullikson and MacCurdy ${ }^{12}$ suggest that serve returns on faster surfaces should be closer to baseline, even when returning faster serves, because staying behind the baseline and making wider moves to strike the ball are not effective strategies in these courts. Takahashi et al. ${ }^{15}$ also found a greater time between serve and return on clay courts, suggesting that on these courts, players stay a few steps back from baseline, in contrast to what is observed on fast courts. Data from the present research confirm results obtained by Gullikson and MacCurdy ${ }^{12}$ and Takahashi et al. ${ }^{15}$, showing that players are more often positioned at IC in fast (hard) surfaces (368 - 39.23\% of serve returns on this surface) than in clay surface $(59-6.60 \%$ of serve returns on this surface) and that players and more frequently positioned at BB on clay courts (835-93.40\%) than on hard courts $(570-60.77 \%)$.

\section{CONCLUSION}

In practical perspective, results from the present study suggest that tennis players should use, or at least seek, game strategies based on aggressiveness and consistency of $1 \mathrm{~S}$ and serve return in a way to force opponents to begin the "uncomfortable" rally. This procedure may facilitate the execution of dominant and more powerful strokes. Serve returns should combine aggression, by IC positioning, and control. Tennis evolution demonstrates that the likelihood of players of beginning rallies in a more defensive position will 
be minimized with a more aggressive serve/return. These characteristics suggest that serve and return are key factors for performance and therefore deserve special attention during tennis players' training.

\section{Acknowledgments}

The authors thank Espaço da Escrita - Pró-Reitoria de Pesquisa - UNICAMP - for the language services provided.

\section{COMPLIANCE WITH ETHICAL STANDARDS}

\section{Funding}

This research was supported by FAPESP (Grant: 2011/50462-5).

\section{Ethical approval}

Not applied. This research had no contact with human beings.

\section{Conflict of interest statement}

The authors have no conflict of interests to declare.

\section{Author Contributions}

Conceived and designed experiments: VPFM, MSA, AM; Performed experiments: VPFM, AFSA, DS; Analyzed data: AFSA, AM; Contributed with reagents/materials/analysis tools: MSA, CDC, DS; Wrote the paper: MSA, CDC, AM.

\section{REFERENCES}

1. Hughes MD, Bartlett RM. The use of performance indicators in performance analysis. J Sports Sci 2002;20(10):739-54.

2. O'Donoghue P, Liddle S. A match analysis of elite tennis strategy for ladies' singles on clay and grass surface. In: Proceedings of the science and racket sports II. London, FN Spon; 1998. p. 247-53.

3. O' Donoghue P, Ingram B. A notational analysis of elite tennis strategy. J Sports Sci 2001;19(2):107-15.

4. Capel-Davies J, Page J, Chong N. ITF approved tennis balls, classified surfaces \& recognised courts 2015. London, International Tennis Federation; 2015.

5. Cross R, Pollard G. Grand Slam men's singles tennis 1991-2009 serve speeds and other related data. ITF Coach Sport Sci Rev 2009;16(49):8-10.

6. Collinson L, Hughes M. Surface effect on the strategy of elite female tennis players. J Sports Sci 2003;21(4):266-7.

7. Hizan H, Whipp PR, Reid M. Validation of match notation (a coding system) in tennis. J Quant Anal Sports 2010;6(3):1-13.

8. Haake S, Rose P, Kotze J. Reaction time testing and grand slam tie-break data. In: Proceedings of the tennis science and technology. Oxford, Blackwell Science; 2000. p. 269-78

9. Gillet E, Leroy D, Thouvarecq R, Stein JF. A notational analysis of elite tennis serve and serve-return strategies on slow surface. J Strength Cond Res 2009;23(2):532-9.

10. Carvalho J, Araújo D, Travassos B, Esteves P, Pesanha L, Pereira F, Davids K. Dynamics of players relative positioning during baseline rallies in tennis. J Sport Sci 2013;31(14):1596-605.

11. Palut Y, Zanone PG. A dynamical analysis of tennis: concepts and data. J Sports Sci 2005;23(20):1021-32. 
12. Gullikson T, MacCurdy D. Fast court tactics - part 2. ITF Coach Sport Sci Rev 2002;28(1):2-3.

13. Kleinoder H, Mester J. Strategies for the return of 1st and 2nd serves. In: Proceedings of the tennis science and technology. Oxford, Blackwell Science; 2000. p. 401-8.

14. Hughes M, Franks I.. Notational analysis: a review of the literature. In: Notational analysis of sport. London: Routledge; 2004. p. 59-106.

15. Takahashi H, Wada T, Maeda A, Kodama M, Nishizono H, Kurata H. The relationship between court surface and tactics in tennis using a computerized scorebook. Int J Perf Anal Sport 2006;6(2):15-25.

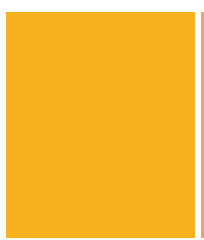

Corresponding author

Dr. Alexandre Moreira

School of Physical Education and Sport

University of Sao Paulo, São Paulo, Brazil.

Av. Prof. Mello Moraes, 65, Cidade Universitária, São Paulo, Brazil.

CEP 05508-030.

Email: alemoreira@usp.br 